\title{
Socio-economic factors associated with the choice of community health workers as contraceptive providers in Rwanda
}

Dieudonne Ndaruhuye Muhoza ( $\square$ dieumu_res@yahoo.fr )

University of Rwanda

Daniel Sebikabu Ruturwa

University of Rwanda

Ignace Habimana Kabano

University of Rwanda

\section{Research Article}

Keywords: Assessing, Community, workers, contraceptive use, Rwanda

Posted Date: February 9th, 2022

DOI: https://doi.org/10.21203/rs.3.rs-1330958/v1

License: (c) (i) This work is licensed under a Creative Commons Attribution 4.0 International License.

Read Full License 


\section{Abstract}

Background: In 2008, Rwanda decided to enhance its community health program in order to further scale up the health system effectiveness. One of the components of the program is the community-based family planning. Between 2010 and 2015, the proportion of women using contraception from the community health workers (CHWs) increased threefold. This study aims at identify the socio-economic factors associated with the choice of CHWs as contraceptive providers in Rwanda in the period 20102015.

Methods: The study uses a pooled dataset from the 2010 and 2015 Rwanda Demographic and Health Surveys. It is restricted to women in union aged 15-49 years. The dependent variable is the source of modern method used at the time of survey. Independent variables include demographic characteristics, socioeconomic factors, and regional variable. Descriptive statistics and multinomial logistic regression are used to assess the association.

Results: The results indicate that the choice of $\mathrm{CHWs}$ is negatively associated with socioeconomic factors (education, economic status, residence, etc) and varies with provinces. The propensities of referring to $\mathrm{CHWs}$ are significantly higher among women with no or low education (odds ratio [OR]: 3.76 and 3.80), women from poor or middle households (OR: 1.20,1.27) or among those living in rural areas (OR: 1.04) than among women with high education, residing in rich households or in urban areas. The Northern Province has recorded the highest adhesion to CHWs (OR: 2.47), followed by the Eastern (OR: 1.88) and Southern (OR: 1.69).

Conclusions: The community health program gained higher approval and adoption among the lower socioeconomic segments of the population. The combined effects of high contraceptive uptake from CHWs among the poor populations and rural residents and that of their predominant share in the total population enable to assume further decline of fertility in Rwanda.

\section{Introduction}

In 2008, Rwanda decided to enhance its community health program, which started timidly in 1995, in order to further improve the health status of the population considered as a key component of the country's development agenda [1]. To achieve this aspiration, the Ministry has recognized the vital role to be played by individuals but also by communities to address health issues, especially the preventable health problems [1-4]. The community health program is viewed as both a preventive and a curative approach because it provides a preventive education to the community with regard to health problems and takes care of those who are sick or facilitates their transfer to appropriate health clinics. The vision of the community health program is to ensure the provision of holistic community health care services tothe entire population.

The advantages of a community health approach are manifold as recognized by several researchers [1,56]. These include (1) empowering communities to participate in the management of their future and 
socioeconomic change; (2) building ownership of programs by the communities; (3) sharing the national benefits equitably among the communities; (4) reducing health related costs; (5) removing different socioeconomic and cultural inequities in health care. Indeed, since the community health workers (CHWs) know the community's beliefs and norms by living and working within it, they have proven to be effective in addressing social barriers, one of the main obstacles to behaviour change in sub-Saharan Africa. Contrary to clinic health facilities, a community health program takes into account the all characteristics of the community, which include the formal and informal networks and support systems, norms, cultural nuances, institutions, politics, and belief systems and use them $[1,7]$.

In Rwanda, one of the components of the community health program is the community based family planning. The rationale to strengthen this program was to achieve the ambitious "Rwanda 2020 vision", whose the objective was to fight poverty and lift Rwanda to a middle income country, by raising the average per capital income from $\$ 290$ to $\$ 900[1,8]$. Expanding access to family planning at the community level was, in addition, a recommendation of several international conferences to reduce unmet needs for family planning and accelerate the achievement of Sustainable Development Goals (SDGs) $[6,9-10]$. In this perspective, the high population growth associated with a fertility level of 6.1 births from the 2005 Demographic and Health Survey (DHS) was considered as a strong obstacle to socioeconomic progress and to the vision. Thus, the Rwandan government declared family planning a key component of socioeconomic transformation, an important contributing factor to the achievement of the 2020 vision and therefore a tool of development [8].

The target of the 2012 family planning policy was to reach $70 \%$ of women of reproductive age using contraception by 2016 from 13\% in 2000 and 17\% in 2005 [11], a very high goal. To expect reaching this objective in a country whose $80 \%$ of the population live in rural areas, the community-based family planning approach appeared as an effective strategy which could increase both access to and acceptance of family planning services, leading to the raise of contraceptive use, even among the poor and rural residents still lagging behind [12-13] and hence the most contributors to the persistent high fertility.

The mission assigned to the community-based family planning program was not only the distribution of some contraceptive methods and referring to health facilities or hospitals the population in need; but also, through Education-Information-Communication, it was to rise the demand for family planning and increase acceptance of contraceptives by removing particularly social barriers still strong in Rwanda [14]. In this regard, each of the 14,837 Rwanda villages (a village[1] accounts for 100-150/200 households) was requested to elect three volunteers from the community members, two females and one male, to act as $\mathrm{CHWs}$ [15]. The elected CHWs were thereafter trained to provide information on all contraceptive methods but to deliver only short acting methods (injectables, pills, condoms, standard days method, etc) which do not require medical expertise.

To our knowledge, up now there is not yet a study that assessed the acceptance and the adhesion of the population to the community health workers program in Rwanda. This study seeks to fill this gap by 
identifying the socio-economic factors associated with the choice of CHWs to get contraceptives in the period 2010-2015 and therefore to define the profile of contraceptive users referring to CHWs. Specifically, the study investigates whether the expected outcome of increasing contraceptive use especially among the lower segments of the population is being met? Findings from this study will shed light on the role of community health program in family planning and help family planning policymakers and providers either to enhance the existing program or to make revision in order to further improve the wellbeing of populations. They shall also stimulate other countries to initiate similar programs and inspire further research.

[1] In Rwanda, a village is the lowest administrative unit existing in both urban areas and rural.

\section{Data And Methods}

\section{Data and Variables}

This study uses a pooled dataset from the 2010 and 2015 Rwanda Demographic and Health Surveys (DHS) [16]. It is restricted to women in union, 15-49 years old, the category of women usually used in the determination of contraceptive prevalence rate. The total sample from both surveys is 13,724 respondents of which 6,834 from the 2010 survey and 6,890 from the 2015 survey. A total of 6,245 respondents, representing $45.5 \%$ of the total sample, were using some modern contraceptives and 7,479 $(54.5 \%)$ were not. Among contraceptive users, $33 \%$ got their contraceptives from $\mathrm{CHWs}$ and $77 \%$ from other sources, i.e. the public and private medical sector.

The dependent variable is the source of any modern contraceptive method, i.e the modern method which was in use at the time of survey. Modern methods are grouped in Short-Acting Methods [SAM] (pills, injections, spermicides, female and male condoms, Days Standard Method, and lactational amenorrhea method), Long-Acting Methods (IUD and implants), and Permanent methods [LAPM] (female and male sterilization). Information on the source of method was obtained from the survey question: "Where did you obtain (current method) the last time"? Answers on sources of contraceptive methods are globally grouped in public medical sector, community health service and private sector. The public medical sector includes all governmental health facilities from the referral hospital to a health post; the community health service includes community health service and outreach service; the private sector includes private medical sector and all other sources of sales or distribution from independent persons (private clinics, private pharmacies, shops, churches, friends, others). In this analysis, the public medical sector and the private sector have been combined in MEDICAL SECTOR because the research focuses on community health program. In this grouping, we oppose what is medical to what is community action.

Independent variables are selected from the theory on factors driving contraceptive use that include woman's characteristics (demographic, social, cultural, economic, etc), household level characteristics, environmental characteristics or surrounding community. As such and given the dataset, the following variables are considered in the analysis: 
- Socio-economic factors: woman's education and her economic status measured by the household wealth index, woman's religion, and her urban or rural residence. Education is defined as the level attained by the respondent. It is grouped in four categories as presented in DHS datasets (none, primary, secondary and higher). Household wealth index variable, usually presented in quintiles, is reduced to three categories (poor, middle and rich) for easy interpretation. The variable religion keeps the three main religions in practice in Rwanda (Catholic, Protestant and Adventist, Muslim) and combines all other cases (other religions, no religion or no declaration) in one category of "others". The residence type distinguishes urban and rural as stated in the surveys according to the official administrative definition.

- Demographic characteristics with direct correlation with contraceptive use. These include woman's age, her desired and actual fertility and child mortality. The variable age is grouped in three categories as such $15-24$ years, $25-34$, and $35-49$. The variables desired fertility and actual fertility comprise each three categories (0-3, 4-5, 6 and above). The variable child mortality distinguishes the categories of no death, one death, two deaths, three deaths or more.

- Regional variable which is the variable "province". It keeps the four provinces of the country and the City of Kigali which has the status of a province. This variable is useful to check the regional variations in the implementation and adoption of the community health program.

\section{Statistical approach and analysis}

As stated in the introductory section, the paper aims to identify the factors associated with the choice of $\mathrm{CHWs}$ as contraceptive providers in order to find out the specific characteristics of contraceptive users who referred to CHWs, who could be called here the most beneficiaries of the program, when compared to those using clinical health facilities (medical sector) or those not using any modern contraceptive. Given this objective, the dependent variable comprises the three above categories: users referring to $\mathrm{CHWs}$, users referring to medical sector, and non- users. As such, the study analysis applies a multinomial logistic regression model for two reasons. First, the multinomial logistic regression is a model that is used to predict the probabilities of more than two possible outcomes of a categorical dependent variable. Second, the three categories of the dependent variable include all possible answers, i.e all respondents. With this inclusiveness, the study assumes the absence of other omitted alternative responses and therefore the variable fulfils the assumption of independence of irrelevant alternatives, an important requirement for the application of a multinomial regression model [17].

In mathematical form, the multinomial regression is generally presented as a set of independent binary regressions. Because the outcome variable has more than two categories, the model has $\mathrm{k}-1$ equations instead of one for a simple logistic regression where k equals to the number of categories. One of the equations is a reference equation and can be any among the k equations. With an outcome variable of three equations, there are two equations as follows: 


$$
\begin{aligned}
& \ln \left(\frac{\operatorname{Pr}\left(\mathrm{Yi}_{1}\right)}{\operatorname{Pr}(\mathrm{Yi}=\mathrm{K})}\right)=\beta_{0}+\beta_{1} \mathrm{X}_{1}+\beta_{2} \mathrm{X}_{2}+\ldots+\varepsilon \\
& \ln \left(\frac{\operatorname{Pr}\left(\mathrm{Yi}_{2}\right)}{\operatorname{Pr}(\mathrm{Yi}=\mathrm{K})}\right)=\beta_{0}+\beta_{1} \mathrm{X}_{1}+\beta_{2} \mathrm{X}_{2}+\ldots+\varepsilon
\end{aligned}
$$

Where $\ln \left(\frac{\operatorname{Pr}\left(\mathrm{Yi}_{\mathrm{i}}=1\right)}{\operatorname{Pr}\left(\mathrm{Yi}_{\mathrm{i}}\right)}\right)$ is the log odds of choosing the category one $(\mathrm{Yi}=1)$ when the reference category is

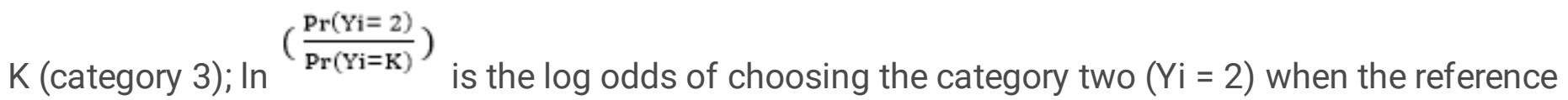
category is $K$ (category 3 ); $\beta_{0}$ is the intercept; $\beta_{1}, \beta_{2}$, etc.are the coefficients of a set of independent variables $\mathrm{X}_{1}, \mathrm{X}_{2}$, etc; and $\varepsilon$ represents the residuals.

The analysis starts with descriptive statistics which are completed with a multinomial logistic regression analysis to establish the association between the selected independent variables and CHWs compared to medical sector and non-users. The analysis performs using STATA version 13 and is adjusted for the effect of complex sample design by applying svy command.

\section{Results}

The presentation of the results starts with the descriptive frequencies of different variables to show the distribution of the sample in different categories of independent variables with reference to the dependent variable. Thereafter, we provide the results from the multinomial logistic regression indicating the associative effects of independent variables on each contraceptive provider.

\section{Descriptive results}

Table 1 presents the results of descriptive analysis providing the distribution of respondents in the three categories of the dependent variable: contraceptive users from medical sector (public or private), contraceptive users who referred to $\mathrm{CHWs}$ and the category of non-use. Out of a total of 13,724 women in union constituting the analytical sample, 35\% are using some contraceptive modern method from medical sector, $10 \%$ are using from the community health service, and $55 \%$ are not using any modern contraceptive method. These proportions computed at national level hide however notable disparities across subpopulations and regions.

Table 1. Distribution of respondents by selected variables according to the source of contraceptive method used 


\begin{tabular}{|c|c|c|c|c|c|}
\hline \multirow[t]{2}{*}{ Variables } & \multirow[t]{2}{*}{ Categories } & \multirow{2}{*}{$\begin{array}{l}\text { Use from } \\
\text { Medical sector }\end{array}$} & Use from & \multirow[t]{2}{*}{ No use } & \multirow[t]{2}{*}{ Total } \\
\hline & & & $\mathrm{CHWs}$ & & \\
\hline & ALL & 35.4 & 9.8 & 54.8 & 13,724 \\
\hline & No education & 28.6 & 9.9 & 61.5 & 2,416 \\
\hline \multirow[t]{4}{*}{ Education } & Primary & 36.1 & 10.6 & 53.4 & 9,528 \\
\hline & Secondary & 40.3 & 6.0 & 53.7 & 1,417 \\
\hline & Higher & 47.1 & 2.5 & 50.4 & 363 \\
\hline & Poor & 31.4 & 10.9 & 57.8 & 5,366 \\
\hline \multirow[t]{3}{*}{ Wealth } & Middle & 36.5 & 10.6 & 52.8 & 5,422 \\
\hline & Rich & 41.0 & 6.1 & 52.9 & 2,936 \\
\hline & Catholic & 37.0 & 11.8 & 51.3 & 5,501 \\
\hline \multirow[t]{3}{*}{ Religion } & Protestant & 34.2 & 8.4 & 57.4 & 7,734 \\
\hline & Muslims & 38.0 & 11.0 & 51.0 & 263 \\
\hline & Others & 37.6 & 7.5 & 54.9 & 226 \\
\hline \multirow[t]{3}{*}{ Residence } & Urban & 39.5 & 7.4 & 53.1 & 2,595 \\
\hline & Rural & 34.5 & 10.3 & 55.2 & 11,129 \\
\hline & $15-24$ & 33.5 & 8.1 & 58.4 & 1,983 \\
\hline \multirow[t]{3}{*}{ Age } & $25-34$ & 38.5 & 11.2 & 50.3 & 6,471 \\
\hline & $35+$ & 32.5 & 8.6 & 58.9 & 5,270 \\
\hline & $0-3$ & 38.0 & 10.3 & 51.7 & 7,112 \\
\hline \multirow[t]{3}{*}{ Desired fertility } & $4-5$ & 33.4 & 9.8 & 56.8 & 5,367 \\
\hline & $6+$ & 29.7 & 6.8 & 63.5 & 1,245 \\
\hline & $0-3$ & 35.1 & 9.9 & 55.0 & 8,308 \\
\hline \multirow[t]{3}{*}{ Actual fertility } & $4-5$ & 37.9 & 10.8 & 51.3 & 3,521 \\
\hline & $6+$ & 32.5 & 7.3 & 60.2 & 1,895 \\
\hline & 0 & 36.6 & 10.3 & 53.1 & 9,816 \\
\hline \multirow[t]{3}{*}{ Child mortality } & 1 & 34.1 & 9.3 & 56.6 & 2,461 \\
\hline & 2 & 31.6 & 7.3 & 61.1 & 882 \\
\hline & 3 & 26.7 & 6.6 & 66.7 & 565 \\
\hline
\end{tabular}




\begin{tabular}{llllll} 
& West & 30.8 & 7.0 & 62.2 & 3,181 \\
\hline \multirow{2}{*}{ Province } & South & 36.6 & 10.5 & 52.9 & 3,384 \\
\hline & Kigali & 40.7 & 5.4 & 53.9 & 1,667 \\
\hline & North & 38.0 & 13.9 & 48.1 & 2,216 \\
\hline & East & 34.4 & 11.2 & 54.4 & 3,276
\end{tabular}

With reference to woman's education, the results indicate that the proportion of women using contraceptives from medical sector rises with education, from $28.6 \%$ among no educated women to $47.1 \%$ among those with higher education. Contrary to contraceptive users referring to medical sector, the proportion of women referring to CHWs to get contraceptives decreases with education from $9.9 \%$ for women with no education to only $2.5 \%$ to those with higher education. On the other hand, the proportion of women not using contraception decreases with education. A similar pattern to education is observed for the economic status of women as measured by the household wealth status. The proportion of women referring to medical sector increases with the raise of socioeconomic status; while it is a reverse pattern for women referring to community health workers. Again, the proportion of women not using modern contraception decreases with the household wealth index. This result goes in line with the existing knowledge that education and economic status facilitate contraceptive practice. Whatever the source of provision, Protestant believers display a lower proportion of women using modern contraception but a higher proposition of non-users, when compared to Catholics, Muslims or others. Women from rural areas exhibit proportionally lower adhesion to medical sector but higher to $\mathrm{CHWs}$ than urbanites: $34.5 \%$ versus $39.5 \%$ and $10.3 \%$ against $7.4 \%$ respectively.

Regarding the demographic characteristics of respondents, the table 1 shows that women in middle reproductive age 25-34 years are more using modern contraception than their counterparts younger or older, irrespective of the source of provision. Use of contraception is inversely correlated to the desired fertility. Women aspiring for fewer children refer to both type of contraceptive providers (38.0\% for medical sector and $10.3 \%$ for $\mathrm{CHWs}$ ) more than those desiring many children. The correlation with the desired number of children changes slightly with the actual children. Irrespective of the source of provision, the proportion of contraceptive users is higher among women with 4-5 children than among those with fewer children or many. Evidently, the pattern of non-users contrasts with that of users. As expected, child mortality affects use of contraception. Regardless of the type of provider, the share of women using modern contraceptives decreases when the number of lost children augments; by contrast, the share of non-users increases steadily with the rise of the number of died children, those who lost many children being much reluctant for the use of contraception.

With respect to regional variations, the high proportions of women using contraception from both medical sector and community health workers program are found in the Northern province $(38.0 \%$ and $13.9 \%$ respectively) while the lower are recorded in the Western province. Kigali as a city shows the highest score of referring to medical sector (40.7\%) but also the lowest adhesion to CHWs score (5.4\%). 


\section{Multinomial logistic regression results}

Table 2 displays the results from the multinomial logistic regression analysis. Since the provision from the community health service is the focus of the study and that the program targets more the lower socioeconomic segments of the population or those living in underserved regions, especially rural regions, the analysis considers as reference category the highest segment of the population for ordinal and discrete variables or those assumed to be as such. Second, the non use option is the omitted category as it represents women who did not respond to the program.

Table 2: Multinomial logistic Regression results in odds ratios (OR) of selected variables on the choice of contraceptive providers 
Medical sector

Community health workers

Variable (ref.) Categories $O R \quad P$. value $\quad<95 \mathrm{Cl} \quad>95 \mathrm{Cl}$ OR P. value $\quad<95 \mathrm{Cl}>95 \mathrm{Cl}$

Constant

$0.93 \quad 0.594$

$0.71 \quad 1.22$

$0.01 \quad 0.000$

0.01

0.03

Year (2015 vs 2010)

$0.76 \quad 0.000$

$0.70 \quad 0.82$

$3.42 \quad 0.000$

2.98

3.93

Education (Higher)

\begin{tabular}{lllllllll} 
No education & 0.61 & 0.000 & 0.48 & 0.79 & 3.76 & 0.000 & 1.84 & 7.67 \\
\hline Primary & 0.80 & 0.054 & 0.63 & 1.00 & 3.80 & 0.000 & 1.89 & 7.62 \\
\hline Secondary & 0.83 & 0.122 & 0.65 & 1.05 & 2.39 & 0.017 & 1.17 & 4.89 \\
\hline HH wealth index (Rich) & & & & & & & & \\
\hline Poor & 0.78 & 0.000 & 0.68 & 0.89 & 1.20 & 0.128 & 0.95 & 1.51 \\
\hline Middle & 0.97 & 0.654 & 0.86 & 1.10 & 1.27 & 0.041 & 1.01 & 1.59 \\
\hline Religion (Catholic) & & & & & & & & \\
\hline Protestant & 0.86 & 0.000 & 0.80 & 0.93 & 0.64 & 0.000 & 0.56 & 0.72 \\
\hline Muslim & 1.00 & 0.982 & 0.76 & 1.31 & 1.08 & 0.713 & 0.71 & 1.67 \\
\hline Others & 0.96 & 0.756 & 0.72 & 1.27 & 0.70 & 0.185 & 0.41 & 1.19 \\
\hline Residence (Rur vs Urban) & 0.94 & 0.307 & 0.82 & 1.06 & 1.03 & 0.752 & 0.84 & 1.27 \\
\hline Age (15-24) & & & & & & & & \\
\hline 25-34 & 1.32 & 0.000 & 1.17 & 1.47 & 1.55 & 0.000 & 1.28 & 1.88 \\
\hline 35+ & 0.92 & 0.226 & 0.79 & 1.06 & 1.00 & 0.996 & 0.79 & 1.27 \\
\hline
\end{tabular}

Actual fertility (0-3)

$\begin{array}{lllllllll}4-5 & 1.49 & 0.000 & 1.34 & 1.64 & 1.46 & 0.000 & 1.24 & 1.71 \\ 6+ & 1.28 & 0.001 & 1.11 & 1.47 & 1.06 & 0.625 & 0.84 & 1.35\end{array}$

Desired fertility (0-3)

$\begin{array}{lllllllll}4-5 & 0.80 & 0.000 & 0.73 & 0.86 & 0.84 & 0.008 & 0.74 & 0.95 \\ 6+ & 0.66 & 0.000 & 0.57 & 0.76 & 0.56 & 0.000 & 0.44 & 0.73\end{array}$

\section{Child mortality (zero)}

\begin{tabular}{lllllllll}
1 & 0.92 & 0.128 & 0.83 & 1.02 & 0.89 & 0.156 & 0.75 & 1.05 \\
\hline 2 & 0.84 & 0.032 & 0.71 & 0.99 & 0.71 & 0.017 & 0.53 & 0.94 \\
\hline 3 & 0.69 & 0.000 & 0.56 & 0.84 & 0.60 & 0.006 & 0.41 & 0.86
\end{tabular}


Province (West)

\begin{tabular}{lllllllll}
\hline South & 1.34 & 0.000 & 1.20 & 1.49 & 1.69 & 0.000 & 1.41 & 2.04 \\
\hline Kigali & 1.19 & 0.029 & 1.02 & 1.39 & 1.13 & 0.417 & 0.84 & 1.52 \\
\hline North & 1.51 & 0.000 & 1.34 & 1.71 & 2.47 & 0.000 & 2.04 & 3.00 \\
\hline East & 1.23 & 0.000 & 1.10 & 1.37 & 1.88 & 0.000 & 1.57 & 2.26
\end{tabular}

Over the five years of study, between 2010 and 2015, results indicate that the choice of medical sector has declined (OR: 0.76 in 2015) while referring to CHWs service increased more than threefold (OR: 3.42), translating both the deployment of CHWs across the country and the adherence of the population to the new contraceptive provider. These overall trends hide important disparities between socio-economic groups.

Educational factor displays opposite effects on the use of medical sector and that of CHWs service. For the former, the raise in education increases the propensities to refer to, from an odds ratio of 0.61 for women with no education to 0.80 for those with a primary level, 0.83 for those who reached a secondary level and to 1.00 for women with higher education (ref. category). For the latter, the raise in education decreases the odds ratios of referring to it, from an odds ratio of 3.76 among women with no education, 3.80 among those with primary, 2.39 among those with secondary to only 1.00 among those with higher education (ref. category). Woman's economic status, as measured by the household wealth index, yields similar pattern to that from education. Other factors held constant, women from the poor or middle indexed households present lower odds (OR: 0.78 , and 0.97 respectively) to refer to medical sector but higher odds (OR: 1.20, and 1.27 respectively) to refer to CHWs when compared to those living in wealthy households (ref category). Women practicing the protestant religion have lower odds to refer to both medical sector (OR: 0.86) and CHWs (OR: 0.64) as compared to those practicing the catholic religion (ref. category) or followers of other religions who behave as Catholics.

On the other hand, women from rural areas who had showed lower frequencies to refer to medical sector and higher ones to use CHWs than those living in urban in descriptive statistics (table 1), exhibit equivalent propensities as urbanites, in the multinomial model, and this for both providers. This means that, after controlling for other factors, especially education and economic status, the difference based on residence disappears. In other words, if rural women were equally educated or wealthy as those in urban, they could behave as their sisters vis-à-vis the use of $\mathrm{CHWs}$ and medical sector.

With regard to demographic characteristics of women, globally there is no significant difference between women choosing the medical sector and those referring to $\mathrm{CHWs}$. However, the variations across subgroups are important. Irrespective of the provider, women in middle reproductive age 25-34 years old or those with four to five children are more likely to use contraception than their sisters younger or older, or those having fewer children less than four or many as six or more. This would mean that the age of a woman and her actual fertility do not intervene in the choice of contraceptive provider. In addition, use of contraception is highly affected by the woman's attitude to family size and the experienced child 
mortality. Regardless of the provider, and other factors held constant, the ORs of using contraception decreases significantly with the desired number of children and the number of children lost. Women wanting many children or who have lost many of their offspring are less inclined to use contraception, irrespective of the provider, than those willing fewer or who didn't lose any child or lost few.

Looking at the regional variations, the results indicate that the general pattern of differentiation by province is identical for the medical sector and $\mathrm{CHWs}$ although parameters are higher for $\mathrm{CHWs}$ than for the medical sector. For example, for the Eastern province the odds ratios are 1.23 for the medical sector and 1.88 for CHWs when compared with the Western province (reference category). Particularly for the $\mathrm{CHWs}$, after controlling for the different socio-economic factors included in the study the Northern Province displays the highest performance (OR: 2.47), followed by the Eastern Province (1.88) and the Southern 1.69). The City of Kigali with an odds ratio of 1.13 , not significantly different from the Western province, is lagging behind the rural provinces.

\section{Discussion}

This research aimed to identify the socio-economic factors associated with the choice of CHWs as contraceptive providers in Rwanda during the period 2010-2015. The purpose was to describe the profile of contraceptive users who are referring to $\mathrm{CHWs}$ as compared to those using medical sector or not using any modern method and so assess whether the objective of the program of increasing contraceptive use among the entire population of Rwanda, especially the underserved populations (poor and rural populations), is being met.

Results from analysis have shown that the community-based family planning program has gained considerable adoption from 2010 to 2015 by which the proportion of women who referred to the program to get contraceptives increased threefold, from $10 \%$ of all contraceptive users to $33 \%$. The choice of this new contraceptives provider is however not equally in the whole population; it varies across subpopulations and between provinces. The $\mathrm{CHWs}$ service is most used by the lower socioeconomic segments of the population (less educated, poor, rural) while the medical sector is most used by the better off people (better educated, rich, urbanites). With regard to demographic characteristics (fertility and mortality) however, the two types of providers receive clients of the same profile. The use of both contraceptive providers increases with actual fertility but decreases with the desired fertility and child mortality level. The similarity among clients vis-à-vis the demographic characteristics is due to the fact that the demographic factors operate mostly for the determination of the demand for family planning than for its satisfaction which is influenced by the socioeconomic position of individuals [18]. Further, results have shown that the provinces which referred more to $\mathrm{CHWs}$ are those with also high provincial contraceptive use [16] indicating that $\mathrm{CHWs}$ should had significantly contributed to the overall national contraceptive level.

The success of CHWs among the less educated, poor or rural populations is not a specificity of Rwanda; it was reported by many researchers using different approaches and scales across the world [3, 9, 19-24]. 
Better than the medical sector, CHWs programs have proven effectiveness in addressing both geographical and social barriers increasing access to and approval of family planning services among the poor populations still predominant in sub-sahara Africa. Furthermore, Stanback et al. [12], Fayemi et al. [25], and Malarcher et al. [26], stressed that the CHWs programs, beyond enhancing access to information and family planning services, ensure a good quality of service delivery and safely as their clinic-based counterparts. Consequently, they shall address the problem of high unmet need for family planning and improve the health and economic conditions of populations accelerating therefore the achievement of several sustainable development goals. The case of Rwanda is an additional evidence that the community-based family planning approach may contribute significantly to expand access to family planning services and increase the overall contraceptive uptake.

In addition to the increasing effect of $\mathrm{CHWs}$ on contraceptive practice, the results have showed that the CHWs program through its higher performance among the poor populations and rural inhabitants could reduce inequities and then inequalities related to place of residence, gender, education and economic position in the access and utilization of family planning services [27]. Recently, Muhoza and Ruhara [28] have demonstrated that in Rwanda, over the same period 2010-2015, the traditional contraceptive differences based on residence or on socioeconomic level were narrowing. This result led these authors to qualify the community-base family planning program a powerful tool for social transformation towards improved quality of life at the community level. Similar finding of promoting equity in access to health services was reported in various settings including Malawi [29], Ethiopia [21] and Australia [20]. In this perspective, CHWs programs could be viewed as a complementary health system to medical sector contributing to the full coverage of the country and to the persuasion of the entire population toward the approval and use of family planning.

While they recognize the undoubtedly positive effects of CHWs program to increase contraceptive use, research has clarified that the performance of the program was depending on the efforts invested in and how the program was locally and culturally contextualized. In Zambia for example, a community health program under an outreach approach in the form of health worker visits improved access to family planning services, but did not address the persistent high fertility desires [30], a result which may imply a lack or a weak educational campaign in the program with regard to family size. In Tanzania, Sheff [31] observed that the increase in access to services was not necessarily catalyzing contraceptive use, but indicated that other factors such as method choice and spousal dynamics were also important components of demand for and use of contraception. In the same line, in the Western region of Kenya, Juma et al. [32] noted that the FP service delivered by CHWs was quite less approved because of limited efforts put into the program. That is why any CHWs approach should be tailored to the needs of the targeted community.

The combined effects of high contraceptive uptake among the poor populations and rural residents from the $\mathrm{CHWs}$ and that of their predominant share in the total population enable to assume further decline of fertility in Rwanda. In Rwanda, around $80 \%$ of the population live in rural areas and most of them are poor [33]. That is why any effort aiming to curb the population growth should be done through the 
support to CHWs program which demonstrated effectiveness in contraceptive use in the large majority of the population who are also the most contributors to the persistent high fertility.

Despite this undeniable success of $\mathrm{CHWs}$ program in raising contraceptive use, some challenges put its sustainability at risk and may limit its performance as noted by Brunie et al. [34]. These include (1) the sustainability of financial resources and contraceptive commodities; (2) the regularity of supervision from hospitals or health centers; (3) the maintaining of motivation of CHWs often working without or with negligible remuneration. To another side, the results from this study raise the question on how far the program attracted new users, those who could not be served by the medical sector. From the dataset used, it was not easy to distinguish the new users from older ones. This limitation calls for further research.

\section{Abbreviations}

CHWs: Community Health Workers; SDGs: Sustainable Development Goals; DHS: Demographic and Health Survey; SAM: Short Acting Methods; IUD: Intra-Uterine Device

LAPM: Permanent methods; OR: Odds ratios

\section{Declarations}

\section{Acknowledgements}

We thank University of Rwanda-Sweden Program/Economics and Management sub-program for its support to present the draft of this manuscript in international conference.

Funding: No funding received for this study

\section{Availability of data and materials}

The data used for this study are from the Rwanda Demographic and Health surveys (DHS) and are publicly available here: https://dhsprogram.com/data/ available-datasets.cfm

\section{Ethics approval and consent to participate}

Since this study was a secondary analysis of the Rwanda Demographic and Health surveys (RDHS) data, which are publicly available, the study did not require any ethics approval. Only DHS program authorization was requested to download the dataset.

\section{Consent for publication}

Not applicable

Competing interests: The authors declare that they have no conflict of interest. 


\section{Authors' contributions}

DNM, DSR, and IHK participated in the conceptualization of the study. DNM and DSR performed the statistical analysis and prepared tables. IHK review the literature which was approved by DNM. DSM and IHK led the interpretation of the results and writing of the draft of the manuscript. All authors read and approved the final manuscript.

\section{Author's information}

${ }^{1}$ Department of Applied Statistics, School of Economics, University of Rwanda, Kigali, Rwanda.

P.O.Box 4285, Kigali Rwanda

\section{References}

1. Ministry of Health (MoH) [Rwanda]. National Community Health Policy. Rwanda, Kigali: MoH; 2008.

2. Sing P, Sachs JD. One million community health workers in sub-Saharan Africa by 2015 . The Lancet. 2013; 382 (9889), 363-365.

3. Perry BH, Zulliger R, Rogers MM. Community health workers in low-, middle-, and high-income Countries: An overview of their history, recent evolution, and current effectiveness. Annual Rev. Public Health. 2014; 35, 399-421. DOI: 10.1146/annurev-publhealth-032013-182354.

4. Tulenko K, Mogedal S, Afzal MM, Frymus D, Oshin A, Pate M, et al. Community health workers for universal health-care coverage: from fragmentation to synergy. Bull World Health Organ. 2013; 91, 847-852. doi: http://dx.doi.org/10.2471/BLT.13.118745

5. Eftekhari BM, Falahat K, Dejman M, Forouzan AS, Afzali HM, Heydari N, Mirabzadeh A. The Main Advantages of Community Based Participatory Health Programs: An Experience from the Islamic Republic of Iran. Global Journal of Health Science. 2013; 5 (3), 28-33. ISSN 1916-9736 E-ISSN 19169744.

6. Perry H, Zulliger R. How Effective Are Community Health Workers? An Overview of Current Evidence with Recommendations for Strengthening Community Health Worker Programs to Accelerate Progress in Achieving the Health-related Millennium Development Goals. Johns Hopkins Bloomberg School of Public Health; 2012. https://www.hrhresourcecenter.org/node/4754.html.

7. Love MB, Gardner K, Legion V. Community health workers: who they are and what they do? Health Education \& Behaviour. 1997; 24(4), 510-522.

8. Ministry of Finance and Economic Planning (MINECOFIN) [Rwanda]. Rwanda Vision 2020. Kigali: MINECOFIN; 2000.

9. East Central and Southern Africa Health Community (ECSA). Expanding Access to Family Planning Services at the Community Level: Findings and Recommendations from a Regional Assessment. Tanzania, Arusha: ECSA, 2011. 
10. World Health Organization (WHO), Global Health Workforce Alliance (GHWFA). Global Consultation on Community Health Workers. Geneva: WHO, GHWFA; 2010.

11. Ministry of Health (MoH) [Rwanda]. National Community Health Strategic Plan July 2013 - June 2018. Kigali: $\mathrm{MoH} ; 2013$.

12. Stanback J, Mbonye AK, Bekiita M. Contraceptive injections by community health workers in Uganda: a nonrandomized community trial. Bulletin World Health Organization. 2007; 85 (10), 768-773. doi: 10.2471/BLT.07.040162.

13. Kalanda B. Repositioning family planning through community based distribution agents in Malawi. Malawi Medical Journal. 2010; 22 (3), 71-74; doi: 10.4314/mmj.v22i3.62191.

14. National Institute of Statistics of Rwanda (NISR) [Rwanda], Ministry of Health (MOH) [Rwanda], and ICF International. Rwanda Demographic and Health Survey 2010. Calverton, Maryland, USA: NISR, $\mathrm{MOH}$, and ICF International; 2012.

15. Condo J, Mugeni C, Naughton B, Hall K, Tuazon MA, Omwega A, et al. Rwanda's evolving community health worker system: a qualitative assessment of client and provider perspectives. Human Resources for Health. 2014; 12 (71). doi: 10.1186/1478-4491-12-71.

16. National Institute of Statistics of Rwanda (NISR) [Rwanda], Ministry of Health (MoH) [Rwanda], and ICF International. Rwanda Demographic and Health Survey 2014-15. Rockville, Maryland, USA: NISR, $\mathrm{MOH}$, and ICF International; 2016.

17. Greene WH. Econometric analysis 7th ed. Boston: Pearson Education, 2012.

18. Ndaruhuye MD, Broekhuis A, Hooimeijer P. Demand and Unmet Need for Means of Family Limitation in Rwanda. International Perspectives on Sexual and Reproductive Health. 2009; 35 (3): 122-130.

19. Jacinto A, Mobaracaly MR, Usta MB, Bique C, Blazer C, Weidert K, Prata N. Safety and acceptability of community-based distribution of injectable contraceptives: a pilot project in Mozambique. Global Health Science and Practice. 2016; 4 (3): 410-421. http://dx.doi.org/10.9745/GHSP-D-16-00133.

20. Javanparast S, Windle A, Freeman T, Baum F. Community health worker programs to improve healthcare access and equity: are they only relevant to low- and middle-income countries? International Journal of Health Policy and Management. 2018; 7 (10): 943-954. doi:10.15171/ijhpm.2018.53

21. Tawye Y, Jotie F, Shigu T, Ngom P, Maggwa N. The Potential Impact of Community-Based Distribution Programmes on Contraceptive Uptake in Resource-poor Settings: Evidence from Ethiopia. African Journal Reprod Health. 2005; 9 (3), 15-26.

22. Scott VK, Gottschalk LB, Wright KQ, Twose C, Bohren MA, Schmitt ME, et al. Community Health Workers' Provision of Family Planning Services in Low- and Middle-Income Countries: A Systematic Review of Effectiveness. Studies in Family Planning. 2015; 46 (3), 241-261. DOI: 10.1111/j.17284465.2015.00028.x.

23. Foreit JR, Raifman S. Increasing access to family planning (FP) and reproductive health (RH) services through task-sharing between community health workers and community mid-level 
professionals in large-scale public-sector programs: A literature review to help guide case studies. Washington, DC: Population Council, 2011.

24. Prata N, Gessessew A, Cartwright A, Fraser A. Provision of injectable contraceptives in Ethiopia through community-based reproductive health agents. Bulletin World Health Organization. 2011. 89 (8), 556-564, doi:10.2471/BLT.11.086710.

25. Fayemi M, Momoh G, Oduola O, Delano G, Ladipo O, Adebola O. Community based distribution agents' approach to provision of family planning information and services in five Nigerian States: A mirage or a reality? African J Primary Health Care Fam Med. 2011; 3 (1).

26. Malarcher S, Meirik O, Lebetkin E, Shah I, Spieler J, Stanback J. Provision of DMPA by community health workers: what the evidence shows. Contraception. 2011; 83 (6): 495-503.

DOI: 10.1016/j.contraception.2010.08.013.

27. McCollum R, Gomez W, Theobald S, Taegtmeyer M. How equitable are community health worker programmes and which programme features influence equity of community health worker services? A systematic review. BMC Public Health. 2016; 16: 419. doi: 10.1186/s12889-016-3043-8.

28. Muhoza ND. Ruhara M C. Closing the Poor-Rich Gap in Contraceptive Use in Rwanda: Understanding the Underlying Mechanisms. International Perspectives on Sexual and Reproductive Health. 2019; 45, 13-23.

29. Masiano SP, Green TL, Dahman BA, Kimmel AD. The effects of community-based distribution of family planning services on contraceptive use: The case of a national scale-up in Malawi. Social Science \& Medicine. 2019; 238 (9549):112490.

30. White SJ, Speizer IS. Can family planning outreach bridge the urban-rural divide in Zambia? BMC Health Services Research. 2007; 7 (143).

31. Sheff MC, Jackson EF, Kante AM, Rusibamayila A, Phillips JF. The impact of adding communitybased distribution of oral contraceptives and condoms to a cluster randomized primary health care intervention in rural Tanzania. Reproductive Health. 2019; 16:181 https://doi.org/10.1186/s12978019-0836-0

32. Juma AP, Mutombo N, Mukiira C. Women's attitudes towards receiving family planning services from community health workers in rural Western Kenya. African Health Sciences. 2015; 15 (1). DOI: http://dx.doi.org/10.4314/ahs.v15i1.22.

33. National Institute of Statistics of Rwanda (NISR) [Rwanda]. Fourth Population and Housing Census, Rwanda 2012: Main indicators report. Kigali: NISR; 2014.

34. Brunie A, Wamala-Mucheri P, Otterness C, Akol A, Chen M, Bufumbo L, Weaver M. Keeping community health workers in Uganda motivated: key challenges, facilitators, and preferred program inputs. Global Health: Science and Practice. 2014; 2 (1), 103-106. DOI: 10.9745/GHSP-D-13-00140. 